\section{MR. DASENT'S REPLY TO MR. LYON.}

To the Editor of The Lancet.

Sir:-Notwithstanding the insinuation* conveyed in your postscript appended to Mr. Lyon's letter, in the last number of THE LANCET, I can assure you I am not influenced by any desire of flourishing in print, and that in my communication respecting Mr. Turnbull's remedies I was actuated purely by the wish of advancing the cause of truth. Mr. Lyon is certainly one of the most valuable instruments in Mr. Turnbull's armoury, for he notonly assiduously "rubs in" to the patients, Mr. Turnbull's endermic remedies, but, on occasion, he even brandishes the pen in his defence. If, however, we are to judge of his proficiency in the former function by his success in the latter, we shall not think very highly of his assistance in the application of his patron's remedies.

The chief complaint I have to advance against Dr. Turnbull is, that in his printed work he has so made use of Mr. Baillie's name, as well as my own, as that any of his readers must suppose both of us to testify to the truth of all the reports; whereas, the fact is, that my testimony refer's merely to the simple history of the cases, exclusive of Dr. Turnbull's conclusions, and that of Mr. Baillie relates solely to the state of three patients, at the termination of their treatment.

Mr. Lyons asserts that $I$ am singularly deficient in memory, but if he will exert his own, he will recollect that my reminiscent faculties were rather too good for his purpose. Can he refuse to acknowledge that he twice requested me to sign a report of the cases modified by himself, and which my perverse memory prevented me from conscientiously doing. With regard to his jompous assertion, that Litera scripta manet, I have only to observe, that he has no writing of mine in his possession which is inconsistent with the tenor of my letter.

I am fully aware, sir, that controversies as to matters of fact can never be satisfactorily terminated on paper; I shall, therefore, not trouble you with any more communications, but I beg to refer any gentleman

* Mr. Dasent misapplies this word with reference to our note. Controversies so rapidly increase on unimportant and personal points, that we only sought to prevent that error on the part of our correspondents, who must be quite sensible of its inutility and impolicy on such occasions as the present; and, indeed, at once to check it, we took the liberty of preventing one or two remarks that were in Mr. Lyon's letter, from appearing in print. However, suppose we let our correspondents have their way on this occasion.-ED. $L$. who may take an interest in the matter to my former letter, in which will be found the true history of each case, as well as the means of finding out the patient, an examina. tion of whom will enable any enquirer to ascertain the comparative correctness of $\mathrm{Mr}$. Lyons' statement and of mine. I am, sir, your obedient servant,

Bury J. Dasent, House-Surgeon.

Westminster Hospital, May 23, 1837.

\section{REVIVAL OF THE CURE OF HY. DROCELE BY INCISION.}

\section{To the Editor of The LANCET.}

SIR :-In the last number of your Journa I observed a paper on the cure of hydrocele by injections of iodine, as recommended by Dr. Stewart, of Calcutta, and Mr. Martin, the discoverer of the remedy. Having seen the abore-mentioned treatment resorted to at the Hôpital La Charité, Paris, may I now presume to offer you a few particulars relative to an old remedy for the same disease, which has been equally successful, and it is that which is at present adopted for the cure of hydrocele at the Hopital St. Louis, by M. Jobert, and approved of by M. Richerand. This remedy, bold as it has been successful, is a reviral by M. Jobert; it is that of incision. Having found the old treatment of injection to fail so frequently, and sometimes to be followed by dangerous consequences, he tried the present mode. He* commences his incision at the anterior and superior part of the scrotum, and continues it down to the most depending part of the tumour, thereby laying it open through its whole extent, and denuding the testes. By continuing the incision thus far, he guards against the possibility of any of the fluid being retained in the scrotum. After evacuating all the effused fluid, he plugs the wound with charpie, and allow $\mathrm{s}$ it to suppurate for some days, from four to seven, after which it is healed by granulation, although it is not M. Jobert's wish to heal the wound by the first intention.

I may here state the curious fact, that in the Parisian hospitals all attempts at healing by the first intention have totally failed. I have seen it essayed at La Charité by Velpeau, after the manner recommeded by Dr. Macartney, of Dublin, and although it was fairly tried it completely failed. M. Velpeau stated, that whether the cause existed in the constitutions of the patients, or in the air of the hospitals, he could not

* Paulus Fgineta commenced his incision at the tumour, and carried it to the upper part of it, in a line parallel to the raphe. 